\title{
First Correlation Study between Family Organizational/ Administrative Functionality Scale Results and School Performance of the Young Human Capital at Public and Private Elementary, Middle and High School of the South/ Center of the US, Territory of Puerto Rico
}

\author{
By Sandra Vélez-Candelario
}

\begin{abstract}
This quantitative study presents the first correlation between Family Organizational and Administrative Functionality and School Performance. To evaluate Family Organizational and Administrative Functionality is using the FOAF Scale (VélezCandelario, S., 2019) and the overall percent of it. This scale has $90 \%$ of the overall value. The intern consistency and the Factor Analysis are, .89 (Cronbach's Alpha) and the Factor Analysis shows a .8 KMO (Kaiser-Mayer-Olkin), recognizing each measured area as an independent factor. To analyze the school performance, we are using the General Point Average (GPA) at the school of each one of the participant. The study includes a socio-demographic document and parent consent. The sample is twohundred-sixty-five (265) children with six (6) to seventeen (18) years old from public and private schools. It was from the south and center zone of Puerto Rico, with an education system based on the American model (Classbase, 2018). The sample is selected by availability from volunteer families and from Puerto Rico's Department of Educationn. The hypothesis investigation $(\mathrm{Hi})$ is: Exist a positive correlation between Family Organizational/Administrative Functionality and school performance. For the statistical analysis, the sample is submitted in the SPSS 26 version and applies a Pearson's correlation formula and a sample descriptive Statistics. The findings show a positive correlation with a significance level of 0.01. The Pearson correlation degree between, FOAF and GPA, is medium, $\rho=.341^{* *}$, (Cohen 1988; in Wuensh 2015). The small correlation effect size is one in which there is a real effect, but one which can only be see-through careful study. A large effect size is an effect which is big enough such that it may be visible to the naked eye (Cohen 1988 in Walker 2007-08). The statistics analysis allowed the acceptance of the Hi confirming the existence of a positive correlation between FOAF Scale results and GPA at School.
\end{abstract}

Keywords: Family, Organizational, Administrative, Functionality, Scale, School, Performance, Correlation.

\section{Introduction}

In some ways, the home management has never been more challenging. The cost of living and the standard of comfort are going up by leaps and bounds. It is essential today to know something about food values and arrangement of meals that avoid monotony and provides the required variety in nourishment on which the excellent health (and, ultimately, the good temper of the household) depend (Ravenhill and Schiff 1911). How can family leaders fulfill these duties as needed

\footnotetext{
${ }^{*}$ CEO, Young Human Capital Research, Corp./Family Organizational Science, USA.
} 
if they are utterly ignorant of the laws of health and child-life? How are they affected by their surrounding environment and all of the other grave and fundamental truths which lie at the root of the successful upbringing and development of the child? Scientific training in Household Administration can alone save the sorely taxed housewife of today from becoming more than a slave to her domestic responsibilities (Ravenhill and Schiff 1911). Progressive social, commercial, industrial, and, last but not least, educational changes now require that this trained intelligence being foster by organized instruction. Such instruction, whether in the fundamental sciences or the applied arts, must be associated with individual practice in laboratory, studio, workroom, and kitchen; the details to be varied as circumstances dictate (Ravenhill and Schiff 1911).

Organizational procedures require intelligent activity, which in turn demands self-control. The human being requires emotional intelligence to acquire selfcontrol. Creative activity during a human being's household organizational and administrative process cannot take place without emotional intelligence. The family organizational and administration style determines how all family members deal with this, and with the consequences of it. This study recognizes the scientific intra-familiar organizational and administrative areas openly. It measures four specific areas that are analyzing in any other form of organization created by human beings like businesses, schools, churches, between others. These four areas are organizational culture, communication, leadership, and the environment. This study recognizes those as part of the management protocol of the intra-familiar setting (Vélez et al. 2016). The study used a mathematics tool named Family Organizational/ Administrative Functionality Scale (Vélez-Candelario 2019) to measure the performance of these four areas inside the household setting using the percent formula, from $0 \%$ to $100 \%$. The overall percentage of the FOAF Scale is correlated with the school's General Point Average (GPA) percent of the each one of the participants at elementary and middle school grades of the South/Center of the US, the territory of Puerto Rico. For the correlation analysis of Family Organizational/Administrative Functionality and the productivity at school, the study used the Statistical Package of Social Science (SPSS 26 version) computer program to introduce the collected data of the General FOAF Percent and the General Point Average at school of each one of the participants to apply a correlation formula.

\section{The Study Area}

This study analyzes the performance and quality of the organizational management and the administrative style in the intra-familiar setting that has young human capital active at school and how this affect their school performance. For the data collection, the study is using the Family Organizational and Administrative Scale (Velez-Candelario 2019) that measures the quality of the four essential organizational areas: Leadership, Communication, Organizational Culture, and Environment. This scale used the percent as the formula to see the quality of each area individually and the commute of each one as a whole 
performance. The study makes a correlation analysis to see if their intra-familiar organizational and administrative performance are influencing in their youngest and active human resources productivity at elementary and middle school grades.

\section{Previous School Performance Studies}

The school performance as a socioeconomic basic need promotes that many scientists try to analyze it as a very relevant topic. According with Trueman (2015), Pierre Bourdieu developed the cultural deprivation theory. This theory implies that higher class cultures are better when compared to working class cultures. Because of this perceived superiority, people from upper and middle classes believe people who are working class are themselves to blame for the failure of their children in education. He argues that working class failure in schools if measured by exam success is the fault of the education system, not working class culture. Cultural reproduction - the major role of the education system, according to Bourdieu, is cultural reproduction. This is the reproduction of the culture of the dominant classes. These groups have the power to impose meanings and to impose them as legitimate. They are able to define their own culture as worthy of being sought and possessed and to establish it as the basis for knowledge in the education system. However, there is no way of showing that they are any better or worse than other subcultures in society.

Other sociologists named Annette Lareau is the author of Home Advantage: Social Class and Parental Intervention in Elementary Education (2000), and coeditor of Social Class: How does it Work? (2009) and Education Research on Trial: Policy Reform and the Call for Scientific Rigor and Journeys (2009). Lareau's work is well known among sociologists, but neglected by the popular media in books like Unequal Childhoods. The sociologists Lareau has been able to capture the texture of inequality in America. She's described how radically childrearing techniques in upper-middle-class homes differ from those in working-class and poor homes, and what this means for the prospects of the kids inside (New York Times 2006-03-09).

Moreover, the journalist Rafal (2010) exposed that the book Home Advantage: Social Class and Parental Intervention in Elementary Education was originally written in 1989 and exposed Lareu's findings. Between those findings he mentioned:

1. Middle class parents do not set out simply to display their cultural resources. They are trying to pass these resources on to their children. They know that children will not automatically attain the same social status as their parents unless they do well in school.

2. Working class parents also believe that their children won't necessarily attain the same social status as themselves, and recognize that doing well in school will help children succeed in later life as well.

3. Working class parents have fewer resources to bring to bear to understand their children's school experience and less confidence to shape it. They see the teachers as professionals and trust them to have the children's best 
interests in mind. They use extrinsic markers like grades, stickers and comments on papers to track how their kids are doing in school. Since teachers almost always try to be positive the parents do not always recognize when a child is falling behind. Middle class parents are more interested in what their child knows and understands than necessarily in the grade mark.

4. Middle class parents differ in the conditions under and the extent to which they activate their cultural resources to shape their children's school experience. Being equally or more educated than teachers they evaluate teachers' performance. They may obtain supplemental experiences (tutoring, lessons, etc.) if they feel their child isn't getting all they need at school and/or they may be more likely to make requests of the school (for special programs, specific teachers, etc...). Middle class parents were most likely to activate their resources for a low-achieving child.

5. Only certain kinds of family involvement are desired by schools. Mainly: nurturing the child at home and sending them to school fed and groomed; reading to them; reviewing papers and homework; reinforcing behavior standards; and respecting the teacher. Families differ in their ability to do these things. Also middle class parents were more likely than working class families to not back up the teacher's discipline and to criticize the school or teacher for their educational program. Working class parents' criticisms were typically not about the academic program. But getting deeply involved in a child's inner life and school career can cause stress for the child and even exacerbate sibling rivalry or even marital tensions for some middle class families.

6. Teachers tried to be fair, but it seems that their expectations and even perceptions of children were colored by the involvement of their parents.

7. Lareau suggests that parent involvement "pays off" more in a school where it is rarer. In a school where most of the parents are busily involved, the parents end up competing for what then become scarce resources.

8. Lareau also looks at the parents' networks, suggesting that the middle class parents were more likely to form relationships with one another whereas working class parents socialized more with their kin groups. Whether among their friends or relatives, middle class parents were more likely to know (or be) change agents like principals, teachers, media, lawyers, judges, between others and thus informally learned how to meet criteria. She suggests teachers might invite an involved working class parent to bring a relative or friend with her the next time she volunteers as an example of how to leverage existing networks into a sort of mentoring system to expand parental involvement among the working class.

9. While this research added to knowledge of an intra-institutional relationship (home to school), it would be interesting in the context to see how a mix of middle and working class families in one school can work well. 
Furthermore Weininger and Lareau (2018), expressed that decades after the publication of Pierre Bourdieu's key works, sociology of education remains the object of persistent misunderstanding. A coherent account of this work must distinguish, at minimum, two phases to Bourdieu's thoughts on education. According with these researchers, during the early period, Bourdieu asserted the salience of both self-selection and institutional selection in shunting students into class destinations that echoed their class origins. In contrast, Bourdieu's later work sought to develop a model of the relation between education and social inequality that had significant cross-national scope. This work de-emphasized the role of selfselection, and developed a substantially more nuanced account of the relation between education and social mobility.

On the other hands, Tena-Sanchez (2016), explained that the methodological individualism and social mechanisms first of all, one of Raymond Boudon's most important contributions to social sciences was his defense of methodological individualism and of causal explanations based on social mechanisms (also called causal or generative mechanisms). That is to say, the principle according to which any macro-social phenomena must be explained as a result of individuals' behaviour, which in turn is the result of these individuals' reasons and motivations. Also in turn, these reasons and motivations can only be understood in refers this is an old idea; Raymond Boudon made a decisive contribution to making this principle the basis of what constitutes an appropriate explanatory strategy in social science. This same researcher explained that Boudon developed this strategy in opposition to pseudo-explanations, either functionalist or structuralist ones as well as exclusively statistical ones, whose paradigmatic example was positivism. $\mathrm{He}$ was always a promoter of empirical sociology and a staunch defender of using statistical tools and formal models. However, he was also critical to the same extent of what has been called variable sociology (Esser 1996 as cited in TenaSanchez (2016), that is to say, the approach by which a phenomenon is explained when we identify a set of independent variables that predict the variance of dependent variables.

Otherwise, Tena-Sanchez (2016) explained scientific nature of social sciences and the study of educational inequalities for Raymond Boudon; the purpose of sociology should not be to move the reader or to make him/her enjoy, nor to transform society through political activism or even to produce data and analyses aimed at making decisions. Boudon was successful in showing how actions and interactions at the micro-level can produce aggregated outcomes at the macrolevel that nobody expects or wishes (perverse effects) without resorting to obscure teleological arguments or employing mere descriptive labels such as "socialization" with explanatory aims.

Is clear that previous scientists try to found scientific reasons or facts that affect the results of the school performance of the young human capital and cannot denied the family role on it, even more this group socioeconomic characteristics. These previous scientific observation also helps to understand the relevance of the family socioeconomic development. Any family organization, according with all these sociologists will have a better at school performance of their young human capital if they also have a better economic circumstance. A better socioeconomic 
development at home is not possible without a good organizational and administrative functionality (Velez-Candelario 2018).

\section{Organizational Behavior and Organizational Theory}

The actions of people at work are called organizational behavior (OB) (Robbins and Coulter 2012). The Organizational Behavior (OB) is focusing on three major areas; individual behavior, group behavior, and organizational aspects. Individual behavior includes topics as attitudes, personality, perception, learning, and motivation. The organizational behavior is concerned with group behavior, which includes: norms, roles, team building, leadership, and conflict. The organizational aspects include structure, culture, and human resources policies and practices. This type of behavior is the focus of the study of psychology as a science (Robbins and Coulter 2012). According to Dictionary.com (2019), organizational psychology is the study of the structure of an organization and of how the people in it interact, usually undertaken in order to improve the organization. Moreover, Hellriegel and Slocum (2009) defined the organizational behavior as the study of the individuals and their groups inside an organizational context and the study of the process and internal practices that influence in the individual's affectivity, their team works, and the organizations. The Collins Dictionary (2019) defines it as the study of the structure of an organization and of how the people in it interact, usually undertaken in order to improve the organization.

Organizational psychology has basics organizational theories to analyze and explain organizational behavior. According to Jeffrey Pfeiffer summarized in New Directions for Organization Theory, organizational theory studies provide an interdisciplinary focus in different areas. Within them, the effects of individual characteristics and action on organization, the performance, success, and survival of organizations, the mutual effects of environments, including resource and task, political, and cultural environments on organizations and vice-versa, and concerns with both the epistemology and methodology that undergird research on each of these topics (Inc. 5000 2019). Another definition exposed that Organizational theory draws from various bodies of knowledge and disciplines. Some types of organizational theories include classical, neoclassical, contingency, systems and organizational structure. The classical perspective of management originated during the Industrial Revolution. It focuses primarily on efficiency and productivity and does not take into account the behavioral attributes of employees; it combines aspects of scientific management, bureaucratic theory, and organizational theory (Bach Pham 2018).

The Neoclassical Organizational Theory is a reaction to the authoritarian structure of the classical theory. It emphasizes the human needs of employees to be happy in the workplace. This theory also allows creativity, individual growth, and motivation, which increases productivity and profits. Managers utilizing the neoclassical approach manipulate the work environment to produce positive results. The Contingency Theory accepts that there is no universally ideal leadership style because each organization faces unique circumstances internally 
and externally. In Contingency Theory, productivity is a function of a manager's ability to adapt to environmental changes. This theory allows managers the freedom to make decisions based on current situations. The Systems Theorists believe all organizational components are interrelated. Changes in one component may affect all other components. Systems theory views organizations as open systems in a state of dynamic equilibrium, which are continually changing and adapting to environment and circumstance. Nonlinear relationships between organizational components create a sophisticated understanding of organizations (Bach Pham 2018).

\section{The Administration Theories and Management}

Administration or management is a daily human activity (Velez-Candelario 2018). The General Administration Theory is the rational conduct of the activities of an organization, with or without profit. It involves planning, organization (structure), the direction and control of all activities differences by the division of labor, running on an organization. Administration Theory is the field of human knowledge that works with the general study of administration, regardless of whether this applies to organizations for-profit or not. The TGA (for its acronym in English), studying the administration of organizations (Chiavenato 2000). The Merriam Webster dictionary (2019a) defined administration as the act or process of administering something; to manage or supervise the execution. Administrative management is concerned with the design and management of an organization. The Administrative management theory attempts to find a rational way to design an organization as a whole. The theory generally calls for a formalized administrative structure, a clear division of labor, and delegation of power and authority to administrators relevant to their areas of responsibilities (Grimsley 2019). According to Grimsley (2019) some of the pioneers of the Scientific Management are:

- Henri Fayol (1841-1925): Fayol was born in France, where he worked for a coal-mining business. He developed 14 administrative principles for organizational structure and management.

- James D. Mooney (1884-1957): Mooney studied mechanical engineering and eventually became a key member of General Motors' top management team. In 1931, he wrote Onward Industry! The book is considered by many scholars to be a significant contribution to organizational management theory.

- Luther H. Gulick (1892-1993): Gulick is often considered the 'Dean of Public Administration.' He applied administrative management theory principles to government.

On the other hands according to Meriam-Webster Dictionary (2019b), management is the act or art of managing: the conduction or supervision of something. To Business Dictionary (2019a), management is the organization and coordination of the activities of a business in order to achieve defined objectives. 
Management involves coordinating and overseeing the work activities of others so that their activities completed efficiently and effectively. We already know that coordination and overseeing the work of others is what distinguishes a managerial position from a non-managerial one. However, this does not mean that managers can do what they want anytime, any ware, or in any way. Instead, management involves ensuring that work activities are completed efficiently and effectively by people responsible for doing them, or at least that is what managers aspire to do (Robbins and Coulter 2012).

Moreover, Robbins et al. (2013), also defined management as the process of getting things done, effectively and efficiently, through and with other people. Several terms of this definition warrant some discussion; process, efficiently, and effectively. The terms process in the definition of management represents the primary activities that supervisors perform. We call these the management functions. According to Henri Fayol, all managers perform five management functions: plan, organized, command, coordination, and control (Dunod 1916 as cited in Robbins et al. 2013). He explained that because organizations exist to achieve some purposes, some has to define that purpose and the means for its achievement. A manager is someone. The planning functions encompass defining an organization's goals, establish an overall strategy for achieving these goals, and developing a comprehensive hierarchy of plans to integrate and coordinate activities. Managers also have to divide work into manageable components and coordinate results to achieve objectives, this is the organizing focus. Finally, when managers motivate their human capital, direct the activities of others, select the most effective communication channel, or resolve conflicts among members, they are engaging in leading.

\section{Supervision and Leadership}

The Business Dictionary (2019b) defined supervisor as the person in the firstline management who monitors and regulates human capital in their performance of assigned or delegated tasks. Supervisors are usually authorized to recommend and effect hiring, disciplining, promoting, punishing, rewarding, and other associated activities regarding the human capital in their departments. To Robbins et al. (2013) the supervisor is the key person, a person in the middle, just other human resources, and a behavioral specialist. They explained that the supervisor as a critical person serves as the critical communication link in the organization chain authority. As a person in the middle, supervisors must interact and reconcile the opposing forces and competing expectations from higher management and the rest of human capital below management. Some people see supervisors as another human resource rather than as management. The behavioral specialist role is one of the essential abilities needed by supervisors. Robbins et al. (2013), explained that the supervisor needs strong abilities in interpersonal skills and that they are looking at as a behavioral specialist.

According to Katz (1974 as cited in Robbins et al. 2013), the supervisors need necessary competencies; technical, interpersonal, conceptual, and political competencies. The technical competencies include; strategic planning, developing 
the organization's overall structure and culture, maintaining relations with major's customers or other organizations. The interpersonal competency is the ability to: work with people, understand their needs, communicate well, and motivate others. The conceptual competency is the mental ability to analyze and diagnose complex situations. These situations include seeing that the organization is a complex system of many interrelated parts and that the organization itself is part of an extensive social system that involves the community and the nation's economy. The political competency is the ability to enhance his or her power, build a power base and establish the "right" connections in the organization.

The leadership subject has so many visions to define it, due of that Kruse (2013) exposed that leadership has nothing to do with seniority or one's position in the hierarchy of a company. Leadership has nothing to do with titles, with personal attributes and is not management (Druker as cited in Kruse 2013). He said that the only definition of a leader is someone who has followers. Bennis (as cited in Kruse 2013) exposed that leadership is the capacity to translate vision into reality. Otherwise, Gates (as cited in Kruse 2013) explained that as we look ahead into the next century, leaders will be those who empower others. Maxwell (as cited in Kruse 2013) defined leadership as an influence - nothing more, nothing less. Leadership is a process of social influence which maximizes efforts of others towards the achievement of a goal (Kruse 2013). Leadership is the ability to demonstrate when somebody influences others to act in a particular way. Thought direction, encouragement, sensitivity, consideration, and support, someone inspires their followers to accept challenges and achieve goals that may be view as difficult to achieve. As a leader, the person is also someone who sees and can get the best out of others- helping them develop a sense of personal and professional accomplishment. Being a leader means building a commitment to goal attainment among those being leading, as well as a strong desire for them to continue following (Robbins et al. 2013).

\section{Household Scientific Administration and Management}

According to Encyclopaedia Brittanica.com (2019), household management refers to the various tasks and chores associated with the organization, financial management, and day-to-day operations of a home. Isabella Mary Mayson (March 12, 1836 - January 1865), universally known as Mrs. Beeton, was the author of Mrs. Beeton's Book of Household Management. In London, she is introducing to Samuel Orchard Beeton, a publisher of books and popular magazines, whom she married on 10 July 1856. Mrs. Beeton began to write articles on cooking and household management for her husband's publications. In 1859-1861, she wrote a monthly supplement to The Englishwoman's Domestic Magazine. In October 1861, the supplements published as a single volume. The Book of Household Management Comprising information for the Mistress, Housekeeper, Cook, Kitchen-Maid, Butler, Footman, Coachman, Valet, Upper and Under HouseMaids, Lady's-Maid, Maid-of-all-Work, Laundry-Maid, Nurse and Nurse-Maid, Monthly Wet and Sick Nurses, etc. etc.-also Sanitary, Medical, \& Legal 
Memoranda: with a History of the Origin, Properties, and Uses of all Things Connected with Home Life and Comfort (Mrs beeton.com 2012).

By the middle of the $19^{\text {th }}$ century, as part of the modern history in America, the scientific administration was everywhere, and women who have the opportunity of the formal education as Marion Talbot held firm convictions about education and the role of women on it. One of only a handful of women in American university administration, she advised female students at the University of Chicago to take full advantage of their academic opportunities. In assuming a new role in society, women needed both personal self-confidence and the best professional education. Talbot expected the University of Chicago to provide these in an environment in which they could be enhancing and developing. Although Talbot advocated a continuing role for women in the home, her views were not traditional. Borrowing from progressive models of efficiency and scientific management and exploiting the new technology appearing at the time, modern women had the domestic tools to escape the drudgery of the past. Marion Talbot taught that a home could be "administered" in an effective way without compromising its vital role as a cultural hearth. Talbot M. argued that equality should mean simply that and nothing else. She expected no more and no less than anyone else received. Her courses in household administration were explicitly open to both men and women, and she criticized decisions that she felt patronized any specific group (The University of Chicago Centennial Catalog 2019).

Furthermore, Shaw (1911, as cited in Ravenhill and Schiff 1911) exposed that the scientific method seeks to establish relations between isolated facts or phenomena, and the relation generally takes the form of cause and effect. $\mathrm{He}$ explained that the persons with scientific training are accustomed to examining the grounds for considering this relation of cause and effect in circumstances which are selected to exhibit the reality of the relation. From that training it becomes possible for them when confronted with circumstances presenting some difficulty, to form a better opinion as to what is the cause of the difficulty that they could if they are confronting with the same difficulty without the previous training. The fact that every person is accustomed to refer every event to some cause; if it is an illness, the occasion for contracting the illness is defining; if it is an unforeseen event in the domestic economy or if a reason is nearly always forthcoming strikes any attentive observer of human nature. Plenty of reasons offered for domestic incidents have no better ground of fact.

Moreover, Shaw (1911 as cited in Ravenhill and Schiff 1911) also talked about a good deal of the comfort of a modern house turns upon a right judgment as regards cause and effect, and therefore some preparation which will fit the household leaders to appreciate the rights and wrongs of domestic reasoning is an indispensable qualification for success. The ability for this is mostly a question of the habit of mind or training; and for our purpose, the training must include those departments of knowledge, the laws of which find daily expression in the diverse experiences of domestic life. The ultimate foundation for these laws is to being found in the study of Physics, which deals with those changes in the state of matter which stop short of the alteration of its composition of Chemistry. This deals with changes involving alteration of the composition of the substances under 
consideration; and of Physiology, which is the identification of the processes which take place in living animals and plants and their relation to the laws of physics and chemistry. Without knowledge of the fundamental principles of these sciences and of the methods by which those principles are establishing, it is not to be expecting that any person can deal adequately with the collective experiences of life.

According with Encyclopaedia Brittanica (2020), another formal pioneer in at home scientific management is Ellen Swallow Richards, (born December 3, 1842, Dunstable, Massachusetts, U.S.—died March 30, 1911, Boston, Massachusetts), American chemist and founder of the home economics movement in the United States, was educated mainly at home. She briefly attended Westford Academy and also taught school for a time. Swallow was trained as a chemist, earning an A.B. from Vassar College in 1870 and, as the first woman admitted to the Massachusetts Institute of Technology (MIT), a B.S. in 1873. Vassar accepted her master's thesis the same year. She remained at MIT for two more years of graduate studies, but she was not awarded a Ph.D. In November 1876, at her urging, the Woman's Education Association of Boston contributed funds for the opening of a Woman's Laboratory at MIT. There, as assistant director under Professor John M. Ordway, she began her work of encouraging women to enter the sciences and of providing opportunities for scientific training to capable and interested women. Courses in basic and industrial chemistry, biology, and mineralogy were taught, and through Ordway a certain amount of industrial and government consulting work was obtained. Richards published several books and pamphlets as a result of her work with the Woman's Laboratory, including The Chemistry of Cooking and Cleaning (1882; with Marion Talbot) and Food Materials and Their Adulterations (1885). From 1876 Richards was also head of the science section of the Society to Encourage Studies at Home.

In 1890, under Richards's guidance, the New England Kitchen was opened in Boston to offer to working-class families' nutritious food, scientifically prepared at low cost, and at the same time to demonstrate the methods employed. From 1894 the Boston School Committee obtained school lunches from the New England Kitchen. Richards lobbied for the introduction of courses in domestic science into the public schools of Boston, and in 1897 she helped Mary M.K. Kehew organize a school of housekeeping in the Woman's Educational and Industrial Union that was later taken over by Simmons College. In 1899 Richards called a summer conference of workers in the fledgling field of domestic science at Lake Placid, New York. Under her chairmanship the series of such conferences held over the next several years established standards, course outlines, bibliographies, and women's club study guides for the field, for which the name "home economics" was adopted. In December 1908 the Lake Placid conferees formed the American Home Economics Association, of which Richards was elected first president. She held the post until her retirement in 1910, and in that time she established the association's Journal of Home Economics. In 1910 she was named to the council of the National Education Association with primary responsibility for overseeing the teaching of home economics in public schools. Among her other published works were Home Sanitation: A Manual for Housekeepers (1887), Domestic 
Economy as a Factor in Public Education (1889), The Cost of Living (1899), Sanitation in Daily Life (1907), and Euthenics: The Science of Controllable Environment (1912).

In today's family and scientific management research, Vélez-Candelario (2018), exposed the full recognition of the organizational psychology theories application and a scientific management method as a tool to develop the family organizational functionality and their socioeconomic development. She also explained that scientific administration theories and organizational psychology theories are capable instruments to apply in the household scenery to increase the efficiency in the daily life activity at the household, preventing divorce and many other psychosocial issues including at work and school performance. According to Vélez-Candelario et al. (2015), if the intra-familiar setting is not capable to administrate and develop their intelligence young human capital to work, stimulating them to be productive at school, the micro and macro economy will receive the consequences of unproductive and dysfunctional future human resources. Indeed, Vélez in her dissertation published on April 2016, as; Family, Human Capital and Industrial/Organizational Psychology, examined if the family as a social organization has the same areas to administrate and organize than the any other organize human social group. In this study tone of the main findings is that the family organization has the same administrative and organizational areas than any other human organization, like the workplace or business setting. Moreover, Vélez-Candelario et al. (2016) found that families have the four organizational areas as any other organize human group; leadership, communication, organizational culture, and environment. She also found that family leaders delineate their mission, their vision, and their goals, even when they do not create a formal organizational policies handbook.

\section{Administration and Development of the Young Human Capital at Home}

In 1964, Nobel Prize winners and University of Chicago economists Gary Becker and Theodore Schultz created the theory of human capital. Becker realized the investment in workers was no different from investing in capital equipment, which is another factor of production. Both are assets that yield income and other outputs. Becker's research focused on education. His found that $25 \%$ of the rise in U.S. per capita incomes from 1929 to 1982 was due to increases in schooling. He pointed out that the cost of education-included time as well as money. People only pursued an education if the potential income gain was greater than the cost. Becker differentiated between general and specific human capital. Specific human capital was training that would only benefit one company. General human capital would benefit the individual at any company. He found that companies would pay for specific human capital while individuals paid the general form. Becker's theory explained how investing in education benefited people, companies, and countries. That theory is supporting by research. States with the highest education scores also have the highest incomes. The top 10 states spend 50\% to $100 \%$ more on education than the average, according to the National Center for Education Statistics (Amadeo 2019). To understand human capital Becker exposed that you 
have to go back to the family, because it is the family that is concerned about their children and try, with whatever resources they have, to promote their children's education and values. Families are the major promoters of values in any free society and even in not-so-free societies. The significant role of human capital in the economy means that policies toward education, health, and other investments are important partly for their implications about economic prosperity, economic growth, and income inequality (Becker 1998).

The administration and development of the human capital do not start at the workplace; it starts at home from their first day of life and continues at school below their family leader's supervision and household psychosocial, cultural and physical influences (Velez-Candelario 2011). According to Encyclopaedia Britannica (2019), Gary S. Becker (1957) is an American economist that applied the methods of economics to aspects of human behavior. Previously he considered more or less the exclusive domain of sociology, criminology, anthropology, and demography. Becker's central premise is that rational economic choices, based on self-interest, govern most aspects of human behavior — not just the purchasing and investment decisions traditionally thought to influence economic behavior. In his dissertation, published in 1957 as The Economics of Discrimination, Becker examined racial discrimination in labor markets, concluding that discrimination has costs for both the victim and the perpetrator. In Human Capital (1964), he argued that an individual's investment in education and training is analogous to a company's investment in new machinery or equipment. In studies such as $A$ Treatise on the Family (1981), Becker analyzed the household as a sort of factory, producing goods and services such as meals, shelter, and childcare. Applying theories of production to household behavior, he was able to make predictions about family size, divorce, and the role of women in the workplace. Subsequent work focused on such subjects as criminal behavior and addiction.

Human Capital and Economic Global Working Group (2012) present The Family Economics and Human Capital in Family research. They exposed that changes in cohort size alone appear to explain a significant fraction of the variation in marriage rates over time. That poverty may be starkly higher at the individual level than it is when measured at the household level only. Parents may underinvest in children not only because they are time constrained, but also because they underestimate the value of such investments. They expressed that a primary function of the family unit is the production of children, with the parental investment of both time and resources being one of the most important inputs. How much investment parents put into children has lasting consequences for the child's human capital development and future earning capacity.

\section{Purpose/Objectives of the Study}

This study was aimed to see the correlation between two variables: Family Organizational and Administrative Functionality Scale results (Velez-Candelario 2019) and the GPA at school of their Young Human Capital in the USA territory of Puerto Rico. In specific terms this study tries to: 
- Understand more precisely what is affecting the productivity levels at the school of the young human capital under the supervision of their family leaders.

- Review the quality of the FOAF Scale (Velez-Candelario, 2019) to collect mathematic data.

- Inquire in this topic of the family administrative and organizational quality management that can affect psychological and socioeconomically the members of this group at school and the rest of their socioeconomic community.

- Understand with a new perspective the productive and unproductive behavior of the young human capital at school.

\section{Research Design}

This study is a quantitative research with a co-rrelational study to analyze the relationships that exist between two specifics variables: Family Organizational and Administrative Functionality and the School Performance using the General Point Average in the group of a young human capital active at elemental and middle school. The population is select from Puerto Rico's public and private educational system; US model system (SE 2020).

\section{Research Questions}

The following research question gave direction to the study:

1. Is the Family Organizational/Administrative Functionality influencing productivity at school?

2. Is the family Organizational and Administrative functionality the Key for better academic performance at home and at school?

3. Is the correlation analysis the first step to understand how much affect the family daily household's environment the productivity at school?

\section{Hypotheses}

- Hi- Organizational and Administrative functionality at home is positively correlated with the Productivity at School of the family young human capital.

- Ho- Organizational and Administrative functionality at home has none correlation with the productivity at school of their young human capital. 


\section{The Study Scope}

This study was delimited to a sample of 265 children between 6 to 17 years old from public and private schools. The participants are from the south and center zone of the US, Territory of Puerto Rico, which has an education system based on the American model (Classbase 2018). The sample was selected by availability from volunteer families and directly from Puerto Rico's Department of Education. They have applied the FOAF Scale as a data collection and a Socio-demographic document that include the General Point Average (GPA) at school. The Family Organizational/Administrative Scale (Velez-Candelario 2019), has a $90 \%$ of overall value. The intern consistency and the Factor Analysis of it are, .89 (Cronbach's Alpha) and the Factor Analysis shows a .8 KMO (Kaiser-MayerOlkin). Using the SPSS (26 version) computer program is submitted a Pearson's Correlation formula with a correlation significance of .05 .

\section{Study Population and Sample Selection}

The population selection process was by availability within private and public system schools collaboration and a single family's student's participation. A collaboration contract with three School Principals of Puerto Rico's Department of Education was completed. A parent's consent document is submitted. The school's principals open the access of their authorized participants at school after receiving their student's adult family leader's signed consent document.

\section{The Data Collection and Pearson's Correlation Analysis Method}

The data collection was complete with a sociodemographic document; it includes the General Point Average at school of each participant. The Family Organizational and Administrative Functionality Scale (Vélez-Candelario, 2018) is applying too. This scale has a $90 \%$ of overall scale value. The Intern Consistency and the Factor Analysis of this scale are .89 (Cronbach's Alpha) and the Factor Analysis process shows a .8 KMO (Kaiser- Mayer- Olkin) by each area that the FOAF Scale measure, recognizing each one as an independent factor. For the statistical analysis, the sample is submitted in the SPSS 26 version and applies Pearson's Correlation formula.

The correlation analysis estimates a sample correlation coefficient, more specifically the Pearson product moment correlation coefficient. The sample correlation coefficient, denoted $r$, ranges between -1 and +1 and quantifies the direction and strength of the linear association between the two variables. The correlation between two variables can be positive (i.e., higher levels of one variable are associated with higher levels of the other) or negative (i.e., higher levels of one variable are associated with lower levels of the other). The sign of the correlation coefficient indicates the direction of the association. The magnitude of the correlation coefficient indicates the strength of the association. For example, a correlation of $r=$ 0.9 suggests a strong positive association between two variables, whereas a correlation 
of $\mathrm{r}=-0.2$ suggest a weak, negative association. A correlation close to zero suggests no direct association between two continuous variables (Introduction to Correlation and Regression Analysis 2019).

The psychosocial phenomenon analysis in this study and how it emerges, Pearson's correlation formula gives us a specific metric that can be mathematically measured. To control and manage the human daily needs and behavior is pertinent to analyze it correctly and useful to received a piece of certain information that anyone can review and used as an effective instrument. This correlation analysis is the result of the Vélez et al. (2016) findings of the essential organizational and administrative areas inside the family as an organized community. The Family as a socioeconomic organization has too many things to do and manage every single day as their young human capital school productivity, school psycho-social development, family leader's governmental relations with the school administrative personnel, the household environment, neighborhoods and community influences, and many others. The family's leaders have to administrate efficiently to reach one of the harder goals, increase their young human capital productivity at school. Productivity is not an instantaneous activity in human life; it has an external or internal stimulation named motivation (Velez-Candelario 2011).

According to the Merriam-Webster dictionary (2019), motivation is a motivating force, stimulus, or influence. For Psychology Today (2019), motivation is the desire to act and move toward a goal. It is the difference between waking up before dawn to pound the pavement and lazing around the house all day. It is the crucial element in setting and attaining one's objectives - and research shows that any person can influence the motivation levels and self-control of others. Motivation might be extrinsic, whereby a person is inspiring by outside forces — other people or things that transpire. Motivation might be intrinsic, whereby the inspiration comes from within a person. Otherwise, Robbins and Coulter (2012), defined motivation as the process by which a person's efforts to energized, directed, and sustained toward attaining a goal, this definition has three key elements: energy, direction, and persistence. So become productive at school or in any other activity that has goals to achieve has to be stimulated from inside and outside.

\section{Results}

The findings show a positive correlation between FOAF and School Productivity (GPA) with a significance level of 0.01 . The Pearson correlation degree between these two variables in this study is medium, $\mathrm{r}=.341$, (Cohen 1988 as cited in Wuensh 2015). The small correlation effect size is one in which there a real effect is but which can only see through careful study. A significant effect size is an effect which is big enough, and consistent enough, that may be able to see it the naked eye (Cohen 1988 in as cited in 2007-08). The statistics analysis allowed the acceptance of the Hi (Hypothesis Investigation) confirming that exist a real and a detectable effect of correlation between FOAF and School Productivity. 
Table 1. Correlation Results (265 N) - GPA and FOAF Scale Results Correlation: in an Elementary and Middle School Grades, Private and Public Education System in the US, Territory of Puerto Rico

\begin{tabular}{|l|c|}
\hline Correlation & $1.344^{* *}$ \\
\hline GPA Pearson Correlation & .000 \\
\hline Sig. (2-tailed) & $.341^{* *} 1$ \\
\hline N 265 265 & .000 \\
\hline FOAF General \% Pearson Correlation & \\
\hline Sig. (2-tailed) & \\
\hline N 265 265 & \\
\hline
\end{tabular}

**. Correlation is significant at the 0.01 level (2-tailed).

Table 2. 265 Sample Descriptive Statistics: Frequency

\begin{tabular}{|c|c|c|c|c|c|c|c|}
\hline \multicolumn{2}{|c|}{$\begin{array}{c}\text { Academic } \\
\text { Level }\end{array}$} & GPA & $\begin{array}{c}\text { FOAF } \\
\text { General } \\
\%\end{array}$ & Leadership & Environment & $\begin{array}{c}\text { Organizational } \\
\text { Culture }\end{array}$ & Communication \\
\hline $\mathrm{N} \mid \frac{\mathrm{V}}{\mathrm{Valid}}$ & 265 & 265 & 265 & 265 & 265 & 265 & 265 \\
\hline Missing & 1 & 1 & 1 & 1 & 1 & 1 & 1 \\
\hline
\end{tabular}

Frequency Table

\begin{tabular}{|l|l|c|c|c|c|}
\hline \multicolumn{7}{|c|}{ Academic Level } \\
\hline \multirow{2}{*}{} & Frequency & Percent & $\begin{array}{c}\text { Valid } \\
\text { Percent }\end{array}$ & $\begin{array}{c}\text { Cumulative } \\
\text { Percent }\end{array}$ \\
\hline \multirow{2}{*}{$\begin{array}{l}\text { Elementary } \\
\text { School }\end{array}$} & 96 & 36.1 & 36.2 & 36.2 \\
\cline { 2 - 6 } & Middle School & 162 & 60.9 & 61.1 & 97.4 \\
\hline \multirow{2}{*}{ Valid } & High School & 7 & 2.6 & 2.6 & 100.0 \\
\cline { 2 - 6 } & Total & 265 & 99.6 & 100.0 & \\
\hline Missing & System & 1 & .4 & & \\
\hline Total & & 266 & 100.0 & & \\
\hline
\end{tabular}

\begin{tabular}{|l|c|c|c|c|c|}
\hline \multirow{5}{*}{} & \multicolumn{5}{|c|}{ GPA } \\
\cline { 2 - 6 } & & Frequency & Percent & $\begin{array}{c}\text { Valid } \\
\text { Percent }\end{array}$ & $\begin{array}{c}\text { Cumulative } \\
\text { Percent }\end{array}$ \\
\cline { 2 - 6 } & $4.00-3.90$ & 77 & 28.9 & 29.1 & 29.1 \\
\cline { 2 - 6 } & $3.89-3.50$ & 33 & 12.4 & 12.5 & 41.5 \\
\cline { 2 - 6 } & $3.49-3.00$ & 51 & 19.2 & 19.2 & 60.8 \\
\cline { 2 - 6 } & $2.99-2.50$ & 13 & 4.9 & 4.9 & 65.7 \\
\cline { 2 - 6 } & $2.49-3.00$ & 71 & 26.7 & 26.8 & 92.5 \\
\cline { 2 - 6 } & $2.19-2.00$ & 6 & 2.3 & 2.3 & 94.7 \\
\cline { 2 - 6 } & $1.99-1.00$ & 14 & 5.3 & 5.3 & 100.0 \\
\cline { 2 - 6 } & Total & 265 & 99.6 & 100.0 & \\
\hline Missing & System & 1 & .4 & & \\
\hline Total & & 266 & 100.0 & & \\
\hline
\end{tabular}




\begin{tabular}{|c|c|c|c|c|c|}
\hline \multirow{4}{*}{} & \multicolumn{5}{|c|}{ School Type } \\
\cline { 2 - 6 } & & Frequency & Percent & $\begin{array}{c}\text { Valid } \\
\text { Percent }\end{array}$ & $\begin{array}{c}\text { Cumulative } \\
\text { Percent }\end{array}$ \\
\cline { 2 - 6 } & $\begin{array}{c}\text { Public } \\
\text { School }\end{array}$ & 232 & 87.5 & 87.5 & 87.5 \\
\cline { 2 - 6 } & $\begin{array}{c}\text { Private } \\
\text { School }\end{array}$ & 33 & 12.5 & 12.5 & 100.0 \\
\cline { 2 - 6 } & Total & 265 & 100.0 & 100.0 & \\
\hline
\end{tabular}

\begin{tabular}{|l|c|c|c|c|c|}
\hline \multicolumn{5}{|c|}{ Leadership } \\
\hline \multirow{5}{*}{ Valid } & & Frequency & Percent & $\begin{array}{c}\text { Valid } \\
\text { Percent }\end{array}$ & $\begin{array}{c}\text { Cumulative } \\
\text { Percent }\end{array}$ \\
\cline { 2 - 6 } & $100-90 \%$ & 132 & 49.6 & 49.8 & 49.8 \\
\cline { 2 - 6 } & $89-85 \%$ & 56 & 21.1 & 21.1 & 70.9 \\
\cline { 2 - 6 } & $84-80 \%$ & 31 & 11.7 & 11.7 & 82.6 \\
\cline { 2 - 6 } & $79-70 \%$ & 30 & 11.3 & 11.3 & 94.0 \\
\cline { 2 - 6 } & $69-25 \%$ & 16 & 6.0 & 6.0 & 100.0 \\
\cline { 2 - 6 } & Total & 265 & 99.6 & 100.0 & \\
\hline Missing & System & 1 & .4 & & \\
\hline Total & & 266 & 100.0 & & \\
\hline
\end{tabular}

\begin{tabular}{|l|l|c|c|c|c|}
\hline \multicolumn{7}{|c|}{ Environment } \\
\hline \multirow{5}{*}{} & & Frequency & Percent & $\begin{array}{c}\text { Valid } \\
\text { Percent }\end{array}$ & $\begin{array}{c}\text { Cumulative } \\
\text { Percent }\end{array}$ \\
\cline { 2 - 6 } & $100-90 \%$ & 117 & 44.0 & 44.2 & 44.2 \\
\cline { 2 - 6 } & $89-85 \%$ & 54 & 20.3 & 20.4 & 64.5 \\
\cline { 2 - 6 } & $84-80 \%$ & 35 & 13.2 & 13.2 & 77.7 \\
\cline { 2 - 6 } & $79-70 \%$ & 39 & 14.7 & 14.7 & 92.5 \\
\cline { 2 - 6 } & $69-25 \%$ & 20 & 7.5 & 7.5 & 100.0 \\
\cline { 2 - 6 } & Total & 265 & 99.6 & 100.0 & \\
\hline Missing & System & 1 & .4 & & \\
\hline Total & & 266 & 100.0 & & \\
\hline
\end{tabular}

\begin{tabular}{|l|c|c|c|c|c|}
\hline \multicolumn{7}{|c|}{ Organizational Culture } \\
\hline \multirow{5}{*}{} & & Frequency & Percent & $\begin{array}{c}\text { Valid } \\
\text { Percent }\end{array}$ & $\begin{array}{c}\text { Cumulative } \\
\text { Percent }\end{array}$ \\
\cline { 2 - 6 } & $100-90 \%$ & 74 & 27.8 & 27.9 & 27.9 \\
\cline { 2 - 6 } & $89-85 \%$ & 34 & 12.8 & 12.8 & 40.8 \\
\cline { 2 - 6 } & $84-80 \%$ & 26 & 9.8 & 9.8 & 50.6 \\
\cline { 2 - 6 } & $79-70 \%$ & 79 & 29.7 & 29.8 & 80.4 \\
\cline { 2 - 6 } & $69-25 \%$ & 52 & 19.5 & 19.6 & 100.0 \\
\cline { 2 - 6 } & Total & 265 & 99.6 & 100.0 & \\
\hline Missing & System & 1 & .4 & & \\
\hline Total & & 266 & 100.0 & & \\
\hline
\end{tabular}




\begin{tabular}{|l|c|c|c|c|c|}
\hline \multicolumn{5}{|c|}{ Communication } \\
\hline \multirow{5}{*}{} & & Frequency & Percent & $\begin{array}{c}\text { Valid } \\
\text { Percent }\end{array}$ & $\begin{array}{c}\text { Cumulative } \\
\text { Percent }\end{array}$ \\
\cline { 2 - 6 } & $100-90 \%$ & 100 & 37.6 & 37.7 & 37.7 \\
\cline { 2 - 6 } & $89-85 \%$ & 50 & 18.8 & 18.9 & 56.6 \\
\cline { 2 - 6 } & $84-80 \%$ & 22 & 8.3 & 8.3 & 64.9 \\
\cline { 2 - 6 } & $79-70 \%$ & 51 & 19.2 & 19.2 & 84.2 \\
\cline { 2 - 6 } & $69-25 \%$ & 42 & 15.8 & 15.8 & 100.0 \\
\cline { 2 - 6 } & Total & 265 & 99.6 & 100.0 & \\
\hline Missing & System & 1 & .4 & & \\
\hline Total & & 266 & 100.0 & & \\
\hline
\end{tabular}

\section{Significance of the Study}

The results of this study reveal the first correlated results between Family Organizational/Administrative Functionality Scale (Velez-Candelario 2019) results and the school performance using the General Point Average (GPA) of the young human capital (children). With this first study, the dilemma of increase the productivity levels at the school of the young human capital can have a new perspective and a new explanation. The family creator or leader has the responsibility to stimulate their active young human capital at school; the need to evaluate the way how they are implementing their at home organizational and administrative system is imperative. This study allows us to see the practical use of the mathematic instrument to measure the quality of the general management and organizational process at home assertively.

\section{Discussion}

After acquiring a positive correlation result between Family Administrative and Organizational Functionality performance and the GPA performance at school is essential concern about the relevance of the family daily administrative basics as one of the medullar activity that stimulates the cognitive capacity in the young human capital at school. These findings allow us to open a new vision of the power of influence of the intra-familiar management activity in their family younger human resources at school. Cohen (1988 as cited in Walker 2007-08) is very clear when explained that the small correlation effect size is one in which there is a real effect but which you can only see through careful study and, that the large effect size is an effect which is big enough or consistent, that you may be able to see with the naked eye (Cohen). It means that in a medium size correlation these two variables are influencing each other affecting the environment of the household setting and their members.

The family is not just an organized human society with the same areas to manage than any other human organization, it is the place where the youngest human resources in the actual economic development put their energies and confidence to become trained and motivated to reach their goals (Vélez, 2016). The way and style of 
the organizational and administrative process have an influence that can make a positive or a negative impact on our young human capital prosperity (VélezCandelario 2011).

\section{Conclusion}

The family leadership style, communication system, physical environment, and organizational culture are medullar areas to manage in the household as in any other human being organization. The management performance of those will define how functional will be the household human capital commitment. The high performance of these areas helps the organizational development of the group giving to the young human capital at school an enjoyable place to rest, work and produce minimizing the stress inside of it and in the school setting. Low stress helps to increase productivity in the workplace and at school. The human beings need a family with healthy and functional family management, where each one of the components feels secure, care, motivated and organize.

\section{References}

Amadeo K (2019) Human Capital and How It Shapes America's Future. Retrieved from https://bit.ly/2zG0EhM. [Accessed 02/13/2020].

Bach Pham L (2018) What Are Organizational Theories? Retrieved from https://bit.ly/ 35edCPr. [Accessed 04/16/2018].

Becker G (1998) Human Capital and Poverty. Religion \& Liberty 8(1). Retrieved from https://bit.ly/2yaccjx. [Accessed 06/18/1019].

Brunsson K (2016) A Dual Perspective on Management. Athens Journal of Business and Economics 2(3): 291-302.

Business Dictionary (2019a) Management. Retrieved from https://bit.ly/2zG12ge. [Accessed 04/24/2019].

Business Dictionary (2019b) Supervisor. Retrieved from https://bit.ly/3cYoEel. [Accessed 04/24/2019].

Chiavennato (2000) Introducción a la Teoría General de la Administración [Introduction of the General Administration Theory], $5^{\text {th }}$ ed. Méjico C.

Classbase (2018) Education System in Puerto Rico. Retrieve from https://bit.ly/2y8B6JF. [Accessed 8/14/2018].

Collions Dictionary (2019) Organizational Psychology. Retrieved from https://bit.ly/2 WmoLKb. [Accessed 04/13/19].

Encyclopaedia Bryttanica (2020) Ellen Swallow Richards. Retrieved from https://bit.ly/ 3bIcE0h. [Accessed 04/21/2020].

Encyclopaedia Britannica (2019) Gary S. Becker: America economist. Retrieved from https:// bit.ly/3f0jErf. [Accessed 04/25/2019].

Encyclopaedia Britannica (2019) Household management. Retrived from https://bit.ly/2y acJLx. [Access 04/26/2019].

Hellriegel D, Slocum JW (2009) Organizational Behavior. $1^{\text {2th }}$ ed. South-Western/ Cengage Learning. 
Human Capital and Economic Global Working Group (2012) Opportunity Family Economics and Human Capital in the Family. Retrieved from https://bit.ly/2y8AJih. [Accessed 04/25/2019].

Inc. 5000 (2019) Organization Theory. Retrieved from https://bit.ly/2KL0Heh. [Access 04/29/2019].

Introduction to Correlation and Regression Analysis (2019) Pearson Correlation. Retrieved from https://bit.ly/2y8ZsD8. [Accessed 03/03/2020].

Kruse K (2013) What Is Leadership? FORBES. Retrieved from https://bit.ly/2yWNagY. [Accessed 04/24/2019].

Lareau A (2000) Unequal Childhoods: Class, Race, and Family Life, $2^{\text {nd }}$ ed., University of California Press.

Merian Webster Dictionary (2019a) Administration. Retrieved from https://bit.ly/3cSzgv2. [Accessed 04/17/2019].

Meriam-Webster Dictionary (2019b) Management.Retrieved from https://bit.ly/3d1Iwgr. [Accessed 4/24/2019].

Merry-Webster (2019) Motivation. Retrieved from https://bit.ly/3bQjNMe. [Accessed 04/11/2019].

Mrs beeton.com (2012) Mrs. Beeton's Book of Household Management. Retrieved from https://bit.ly/3bNSgL9. [Accessed 04/25/2019].

Psychology Today (2019) Motivation. Retrieved from https://bit.ly/2ySwEPc. [Accessed 04/11/19]

Rafal C (2010) Notes from Home Advantage by Annette Lareau. April, 24, 2010.Retrieved from https://bit.ly/3aPK2km. [Accessed 04/17/2020].

Ravenhill A, Schiff CJ (1911) Household Administration: Its place in the higher education of women. E.Book: \#36781. ISO-8859-1. Retrieved from https://bit.ly/ 3AqWQqB. [Accessed on 04/17/2019].

Robbins SP, Coulter M (2012) Management, $11^{\text {th }}$ ed. New Jersey: Pearson. ISBN: 978013

Robbins SP, DeCenzo DA, Wolter R (2013) Supervision Today! $7^{\text {th }}$ ed. New Jersey: Pearson. ISBN-13:978-0-13-278403-0.

Grimsley S (2019) What Is Administrative Management Theory?. Chapter 1. Lesson 5 Retrieved from https://bit.ly/2YgP5rG. [Accessed 04/17/2019].

SE (2020) Education in Puerto Rico. Retrieved from https://bit.ly/3f0l6Kd. [Accessed 04/21/2020].

The University of Chicago Centennial Catalog (2019) Marion Talbot: Household administration. Retrieved from https://bit.ly/3eYkV25. [Accessed 04/25/2019].

Tena-Sanchez J (2016) Raymond Boudon: An analytical social theorist. Retrieved from https://bit.ly/2zGGsMH. [Accessed 03/03/2020].

Trueman CN (2015) Pierre Bourdieu. historylearningsite.co.uk. The History Learning Site, 22. 18 Dec 2019. Retrieved from https://bit.ly/2KH52PA. [Accessed on: May 2015].

Vélez-Candelario S (2011) Construcción de Primera Escala que Mide Funcionalidad Organizacional Familiar: Para la Salud de la Gente [Construction of the first scale that Measure family organizational and administrative functionality]. XXXIII Convención Sociedad Interamericana de Psicología. Medellín, Colombia.

Vélez-Candelario S (2018) Human capital productivity: a family challenge. In Human Capital: Perspectives, Challenges and Future Directions, M Lawrence, F.Murray (eds), 145-159. New York: Nova Science Publishers.

Vélez-Candelario S (2019) Construction and validation of the first scale that measures family organizational and administrative functionality. Athens Journal of Social Sciences 6(4): 291-304. 
Vélez S, Rosario I, Méndez V, Vargas L (2016) Family, human capital and industrial/ organizational psychology. Interamerican Journal of Psychology 50(3) Retrieved from https://bit.ly/3eVsV45.[Accessed 04/29/2019].

Vélez S, Rosario I, Méndez V, Vargas L (2015) Family, human capital and i/o psychology; tending bridges. Proceedings: XXXV Interamerican Society of Psychology Congress, Page 339. PUCP, Lima, Perú. 12/16-07-2015

Walker I (2007-08) Null Hypothesis Testing and Effect Sizes. Statistics for Psychology: Making sense of our world through analysis. Retrieved from https://bit.ly/3eZ7n Dz.[Accessed 8/14/2018].

Weininger EB, Lareau A (2018) Pierre Bourdieu's Sociology of Education: Institutional Form and Social Inequality. Thomas Medvetz and Jeffrey J. Sallaz (eds). Retrieved from https://bit.ly/2YmovNT. [Accessed 04/17/2020].

Wuensch K (2015) Cohen's Conventions for small, medium and large effects. East Carolina University. Retrieved from https://bit.ly/2VL1hyW. [Access 08/14/2018]. 